\title{
Application of Wireless Power Transfer Technologies for Soil Temperature Measurement System of Reinforced Soil Wall in Cold and Snowy Environments
}

\author{
Akinobu Ogasawara, ${ }^{1}$ Shunzo Kawajiri, ${ }^{2 *}$ Teruo Fujiwara, ${ }^{3}$ \\ Naoya Momohara, ${ }^{4}$ Masato Sakurai, ${ }^{4}$ and Koshiro Matsushita ${ }^{1}$ \\ ${ }^{1}$ Graduate School of Engineering, Kitami Institute of Technology, \\ 165 Koen-cho, Kitami, Hokkaido 090-8507, Japan \\ ${ }^{2}$ Faculty of Engineering, Kitami Institute of Technology, 165 Koen-cho, Kitami, Hokkaido 090-8507, Japan \\ ${ }^{3}$ SHO Engineering Corp., 2-14-9 Takanawa, Minato-ku, Tokyo 108-0074, Japan \\ ${ }^{4}$ OYO Corporation, 43 Miyukigaoka, Tsukuba, Ibaraki 305-0841, Japan
}

(Received March 2, 2021; accepted June 17, 2021)

Keywords: wireless power transfer (WPT), soil temperature, reinforced soil wall, cold and snowy environment

Reinforced soil walls, which are civil engineering structures, are subjected to catastrophic collapse when concrete panels fall off in cold and snowy environments. One of the methods to predict such collapse is soil temperature monitoring of the reinforced soil wall. However, in cold and snowy environments, health monitoring requires a lot of effort because the snow load breaks the wires connecting the data logger to the sensors, whereby the collected data fail to reach the logger. In this study, we developed a prototype wireless and battery-free soil temperature measurement system using wireless power transfer (WPT), and conducted field observation experiments for about nine months on a full-scale test reinforced soil wall and an in-service highway. The seasonal variation of the temperature data obtained from the WPT method was consistent with that of the temperature data obtained continuously by the traditional method.

\section{Introduction}

Reinforced soil walls are one of the most common geotechnical structures in transportation infrastructure such as roads, railroads, bridges, and tunnels. Figure 1 shows an example of the general structure of a reinforced soil wall, which consists of concrete panels of about $200 \mathrm{~mm}$ thickness and reinforcement made of steel or polymeric materials. ${ }^{(1-3)}$ By balancing the frictional force of the reinforcement against the pressure exerted by the earth when the wall is about to collapse due to gravity, a vertical or near-vertical structure can be constructed. In recent years, the number of construction projects using reinforced soil walls has been increasing because of the effective use of leftover soil from civil engineering works and because the construction cost is lower than that of reinforced concrete structures. However, collapses such as that shown in

*Corresponding author: e-mail: skawajiri@mail.kitami-it.ac.jp https://doi.org/10.18494/SAM.2021.3350 
Fig. 2 have been reported in cold and snowy environments. ${ }^{(4)}$ Such collapses, in which concrete panels fall off, are serious problems that have not occurred even after earthquakes or record rainfall. The reason for the collapses is thought to be that the freezing pressure (i.e., expansion pressure) caused by the freezing of the soil, which is characteristic of cold and snowy environments, exerts an excessive tensile force on the reinforcement, causing its fracture. ${ }^{(5)}$ For this reason, we constructed a full-scale reinforced soil wall for testing and conducted dynamic observations outdoors. As a result, a large tensile force was observed to act on the reinforcement as the freezing area expanded into the reinforced soil wall. Therefore, it is important to observe the temperature distribution in the reinforced soil wall as one of the parameters to detect the possibility of collapse in advance. However, in the past, temperature sensors and data loggers were wired to each other, and a terminal such as a laptop PC had to be connected to the data

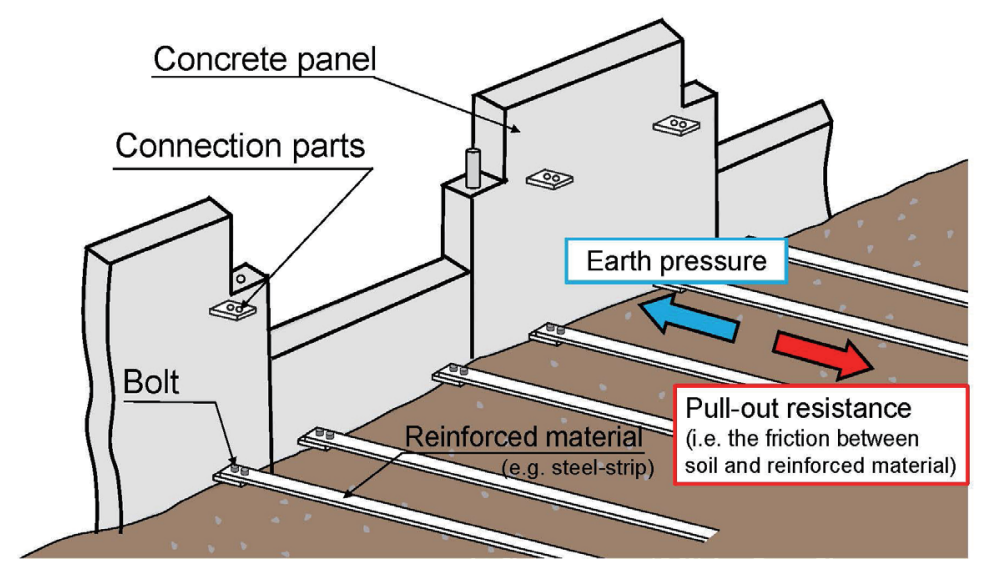

Fig. 1. (Color online) Overview of reinforced soil wall using strip.

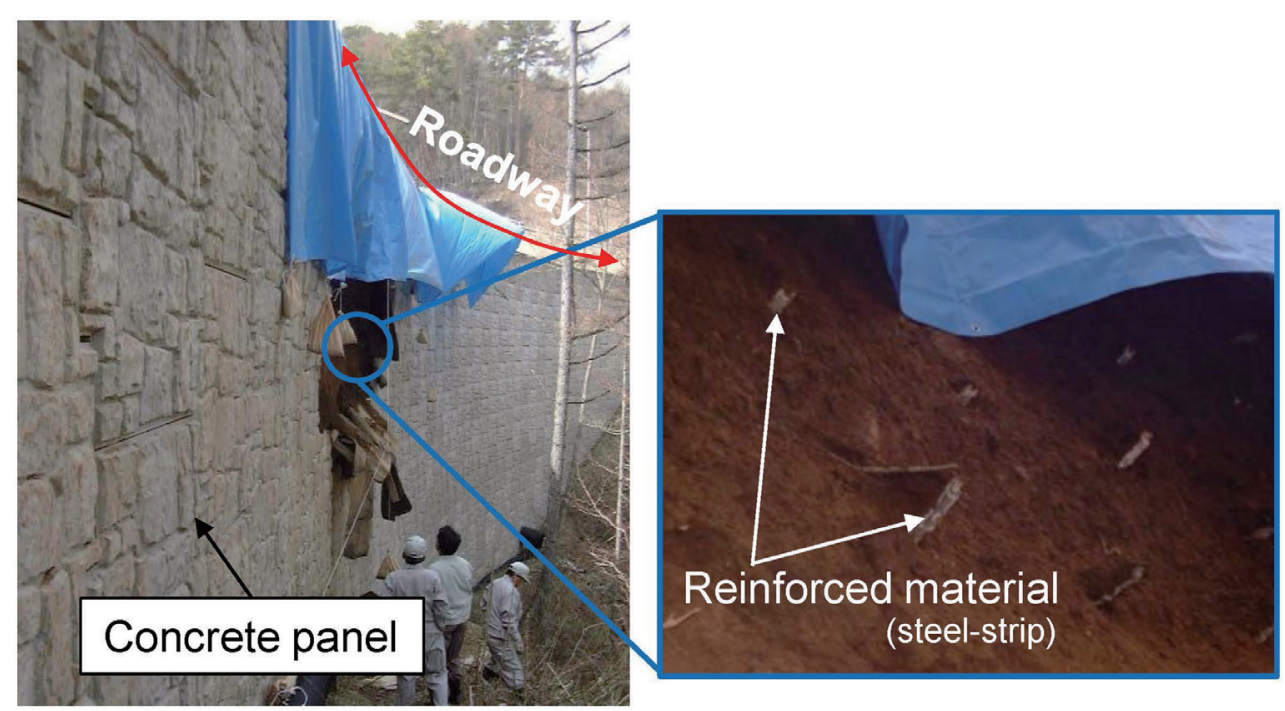

Fig. 2. (Color online) Collapse of reinforced soil wall in cold and snowy environment. 
logger to collect the data. ${ }^{(5)}$ Such a method is dangerous in places such as highways. In addition, in cold and snowy areas, snow accumulation makes it difficult to reach the data loggers. Moreover, the temperature changes rapidly in cold and snowy areas, quickly depleting the batteries of data loggers. Therefore, it is necessary to construct a maintenance-free observation system that collects observation data from data loggers wirelessly and does not require batteries. To solve these problems, we focused on wireless power transfer (WPT), ${ }^{(6-9)}$ which is being widely commercialized. In particular, the use of WPT has rapidly expanded to include mobile phone chargers and stationary charging electric vehicles (EVs). ${ }^{(10)}$ Studies are being conducted on the applicability of WPT systems to unmanned aerial vehicles (UAVs) in large-scale wireless sensor networks (WSNs) and as the power supply to railroad vehicles. ${ }^{(11)}$ However, there has been little research on the application of WPT to the health monitoring of civil engineering structures such as those targeted in this study. ${ }^{(12,13)}$ As an example of one such study, Shams and Ali reported an experiment where wireless power was transmitted to a rectenna buried in concrete or pavement materials. They found that for a rectenna buried within $30 \mathrm{~mm}$ of concrete, the received DC power was $10.37 \mathrm{~mW}$, which was about $70 \%$ of the received DC power in free space. ${ }^{(12)}$ However, there are no reports on the application of WPT to geotechnical structures or the measurement of full-scale structures. In particular, the measurement of full-scale structures has been indicated by Shams and Ali as the tasks for future research, which is important for the popularization of WPT.

Here, we conducted a basic study on the development of a temperature measurement system based on WPT technology and compared the accuracy of the WPT-based temperature measurement system and a traditional data-logger-based temperature measurement system by collecting data on an in-service freeway and a full-scale test reinforced soil wall. The consistency of the two systems and their durability in cold and snowy regions were also compared.

\section{Test Instrumentation and Location}

\subsection{WPT system and soil temperature probe}

The basic concept of the WPT system in this study is similar to that of the conventional method. ${ }^{(14)}$ Figure 3 shows the WPT temperature measurement system in this study, which consists of a remote temperature measurement unit (master unit), battery-free temperature sensor unit (slave unit), and a temperature sensor probe. Tables 1 and 2 respectively show the main performance parameters of the remote temperature measurement unit and the battery-free temperature sensor unit shown in Fig. 3. The battery-free slave unit operates with the RF power provided by the master unit. It consists of an RF/DC power converter loaded with an input radio power reflection controller, a DC power stored capacitor with voltage control, and a CPU for temperature data reading and sub-carrier phase modulation for data transfer to the master unit by the backscatter communication method. ${ }^{(15)}$ The temperature sensor probe with four temperature sensors is buried in the soil inside the reinforced soil wall. The slave unit is installed beside the reinforced soil wall. On the other hand, the master unit consists of a transmitter that sends RF power to the slave unit, a receiver that receives temperature data from 


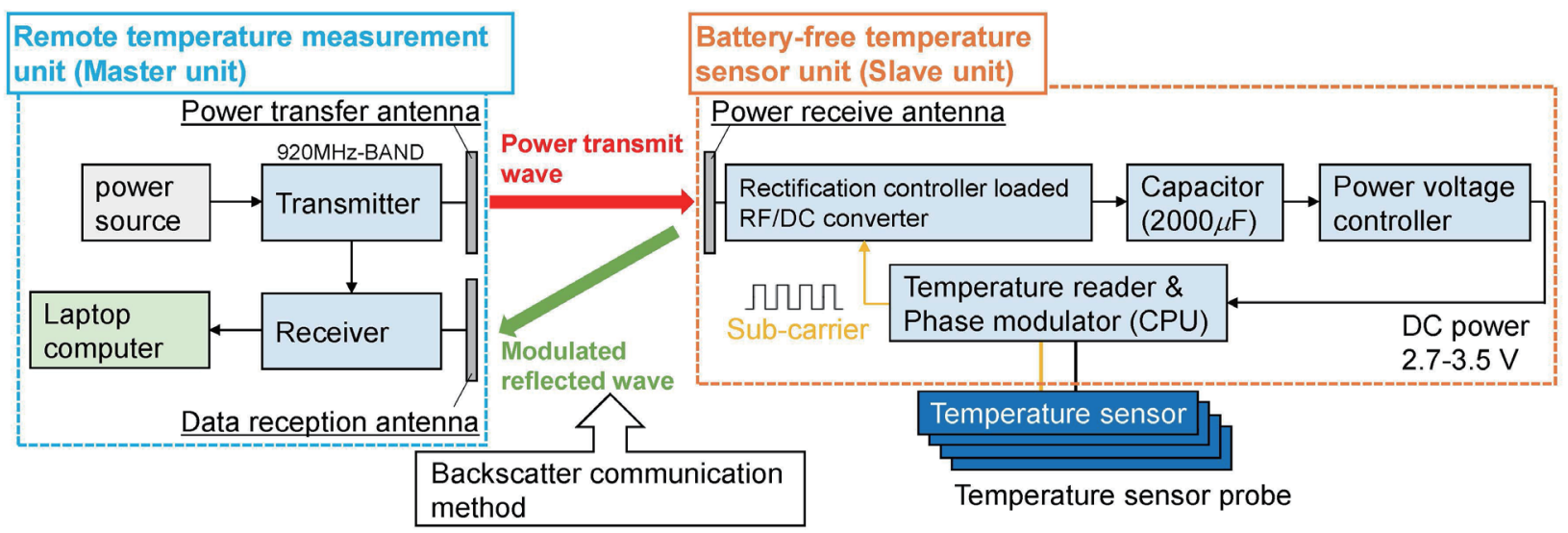

Fig. 3. (Color online) Configuration diagram of soil temperature measurement system using WPT.

Table 1

Specifications of the remote temperature measurement unit (master unit).

Microwave power transmitter

Transmission frequency

Transmission power

Transmission antenna

Transmission antenna gain

Reflection signal receiver

Receiving signal frequency

Receive antenna

Receive antenna gain

Detection method

\section{$929 \mathrm{MHz}$}

$7.4 \mathrm{~W}$

Circularly polarized microstrip array antenna four-element array

$12.0 \mathrm{dBi}$

Homodyne detection

$929 \mathrm{MHz}$

Circularly polarized microstrip antenna

$6.19 \mathrm{dBi}$

Homodyne detection

Table 2

Specifications of the battery-free temperature sensor unit (slave unit).

Microwave power receiver and RF-DC

conversion (rectenna)

Reflected wave frequency

Receive antenna

Receive antenna gain

RF-DC conversion

Power storage

Data reading and data transmission

Temperature reading time

Data transmission

Data transmission rate

Sub-carrier frequency

Modulation

Modulation loss
$929 \mathrm{MHz}$

Air layer patch antenna, circularly polarized wave

$$
8.2 \mathrm{dBi}
$$

Self-biased half-wave rectifier

Condenser $2000 \mu \mathrm{F}$

$$
250 \mathrm{~ms}
$$

Modulated backscatter

1024 bps

$16.384 \mathrm{kHz}$

Binary phase shift keying (BPSK)

$-20 \mathrm{~dB}$ (Re-radiation power) 
the slave unit, and a PC that records demodulated data from the receiver. The WPT temperature measurement system requirements are as follows: temperature measurement range, temperature measurement accuracy, number of temperature measurement points, intermittent measurement, standby time, and measurement distance.

In this study, the $920 \mathrm{MHz}$ band is used for the transmission frequency of the WPT temperature measurement system. This is because similar technologies and RFID use the $920 \mathrm{MHz}$ band without a license, and there is a high possibility that the proposed system will be able to use the same band without the radio station license in the future by promoting power saving. To create a battery-free slave unit, it is necessary to reduce the power consumption of the slave unit. Therefore, the $\mathrm{I}^{2} \mathrm{C}$ interface was selected as a power-saving temperature sensor, and the backscatter communication method was adopted instead of a transmitter with high power consumption. ${ }^{(15)}$ Intermittent measurement is acceptable for temperature measurement because there are no real-time restrictions. For this reason, the slave unit uses a power storage measurement method, and consideration is given to keeping the transmitted power small to reduce interference with the communication system. Moreover, to suppress the spatial propagation loss of wireless power transmission, a high-gain antenna is used for both power transmission and power reception.

In the slave unit, the radio power from the master unit received by the power receive antenna is converted into DC power by the reflection controller loaded RF/DC converter and stored in the capacitor for storage. When the capacitor voltage reaches $3.5 \mathrm{~V}$, the temperature sensor is activated by the DC power supplied by the power voltage controller to the temperature reader and the phase modulator. The temperature reader activates the temperature sensor and reads the quantized temperature data from the temperature sensor. The phase modulator generates a wave of $16.349 \mathrm{kHz}$ in the sub-carrier, and the phase modulates the read temperature data at $1024 \mathrm{bps}$. The phase-modulated sub-carrier is superimposed on the reflected wave of the transmitted radio wave by the reflection controller, and the data is transmitted to the master unit. The above operation is repeated until the capacitor for storage drops to the minimum operating voltage of $2.8 \mathrm{~V}$ for the temperature reader and phase modulator. In the master unit, the modulated reflection wave is demodulated by homodyne detection at the receiver, the temperature data is extracted and it is stored in the memory of the PC.

Figure 4 shows the soil temperature probe for WPT fabricated in this study. Table 3 shows the specifications of the temperature sensors attached to the soil temperature probe. The four temperature sensors are electrically connected by an $\mathrm{I}^{2} \mathrm{C}$ interface, and the distance from the modulation control circuit for measurement to the most distant sensor is $8 \mathrm{~m}$. A pull-up resistor is set to minimize the power consumption without affecting the communication at this distance.

Table 4 shows the measured power consumption and integrated power consumption for one measurement of the soil temperature with the four temperature sensors and transmission of these measured data to the master unit by backscatter communication. The integrated power required for one temperature measurement and for transmission of the measured data to the master unit is $3.9 \mathrm{mWs}$, while the power capacity stored in the capacitor of $2000 \mu \mathrm{F}$ is $5 \mathrm{mWs}$ when the capacitor is charged between 2.8 and $3.5 \mathrm{~V}$, providing a power capacity margin of about $30 \%$. 


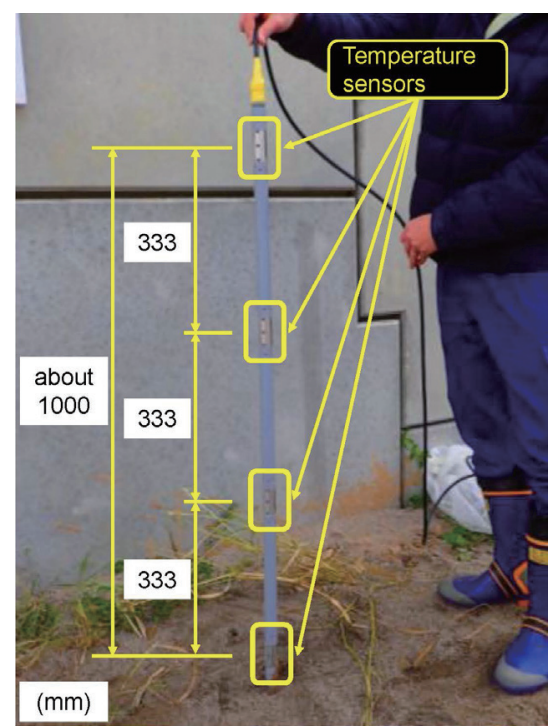

Fig. 4. (Color online) Soil temperature probe used in WPT method.

Table 3

Principal specifications of the temperature sensor.

\begin{tabular}{lc}
\hline Item & Performance \\
\hline Operating temperature range & $-55-150^{\circ} \mathrm{C}$ \\
Accuracy & $\pm 0.5^{\circ} \mathrm{C}\left(-40-105{ }^{\circ} \mathrm{C}\right)$ \\
Power source voltage & $2.7-5.5 \mathrm{~V}$ \\
Consumed power & $700 \mu \mathrm{W}$ \\
Communication interface & $\mathrm{I}^{2} \mathrm{C}$ \\
\hline
\end{tabular}

Table 4

Amount of power required for one temperature measurement.

\begin{tabular}{lccc}
\hline Event & Consumed power $(\mathrm{mW})$ & Time $(\mathrm{ms})$ & Power consumption $(\mathrm{mWs})$ \\
\hline Temperature measurement & 3.5 & 250 & 0.88 \\
Data transmission & 21.0 & 144 & 3.02 \\
\hline Total & - & - & 3.90 \\
\hline
\end{tabular}

To operate the temperature reader and phase modulator, it is necessary to charge the storage capacitor to $3.5 \mathrm{~V}$. Figure 5 shows the measured characteristic of the RF/DC conversion of the rectifier. To charge the storage capacitor to $3.5 \mathrm{~V}$, the output voltage of the RF/DC converter must be $3.5 \mathrm{~V}$ or higher, and the input power corresponding to this value is $2 \mathrm{dBm}$. Figure 6 shows the charging time when charging the capacitor voltage for storage from 2.8 to $3.5 \mathrm{~V}$ with input power of $3 \mathrm{dBm}$. It takes about $10 \mathrm{~s}$ to charge the capacitor voltage for storage to $2.8-3.5 \mathrm{~V}$. Figure 7 shows the relationship between the transmission distance in free space and the receive power of the slave unit. This relationship is calculated from the transmission power, the transmission antenna gain, and the receive antenna gain shown in Tables 1 and 2. The minimum receiving power (i.e., the rectifier input power) at which the battery-free temperature sensor unit 


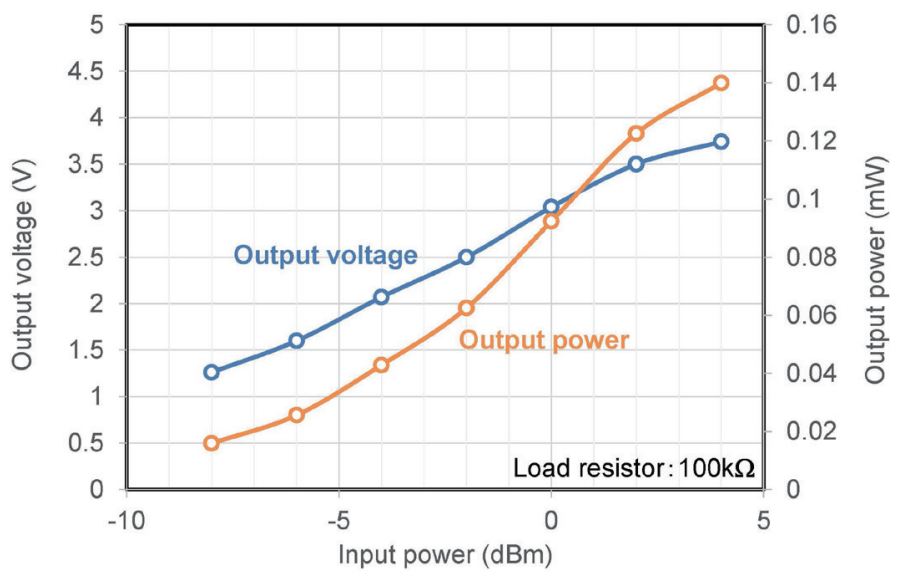

Fig. 5. (Color online) Characteristic of RF/DC conversion of rectifier.

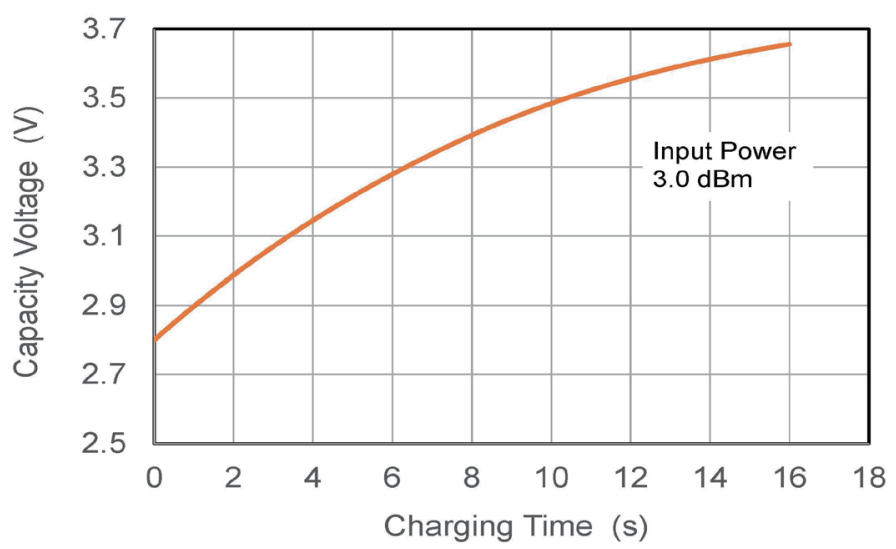

Fig. 6. (Color online) Relationship between charging time and capacitor voltage.

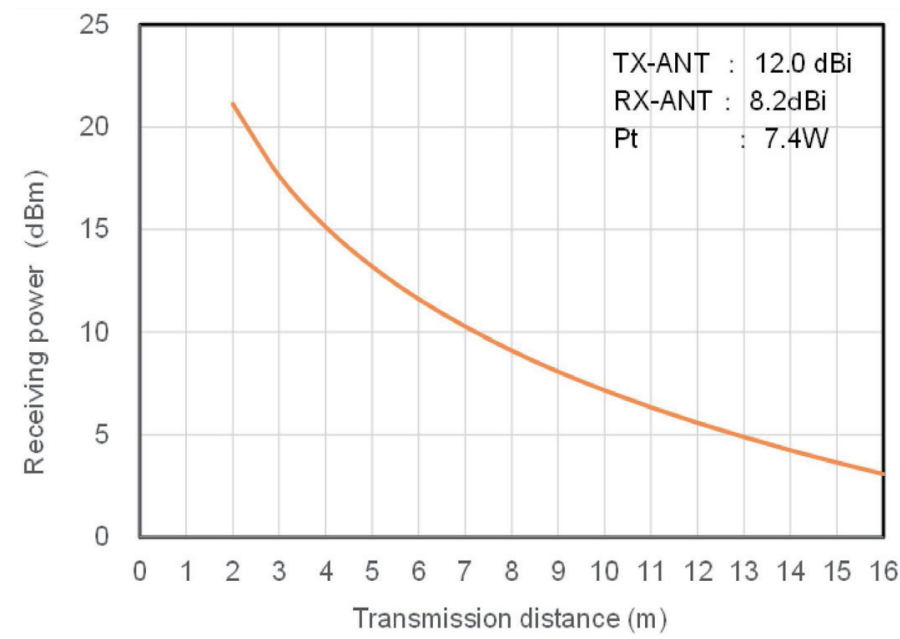

Fig. 7. (Color online) Relationship between transmission distance and receiving power of battery-free temperature sensor unit. 
can operate is $3 \mathrm{dBm}$. The transmission distance corresponding to $3 \mathrm{dBm}$ is about $16 \mathrm{~m}$. Input power corresponding to an output voltage higher than $3.5 \mathrm{~V}$ is required for charging the storage capacitor.

Wireless power and data transmission tests of the above WPT system were conducted in an anechoic chamber. When the remote measurement distance was $10 \mathrm{~m}$, the received power was about $7 \mathrm{dBm}$ and the measurement interval was about $2.2 \mathrm{~s}$. The results of this experiment were generally as expected. In addition, we obtained a radio station license before starting the observation because a radio station license is required to operate the WPT system constructed in this study.

\subsection{Test site (reinforced soil wall)}

In this study, temperature measurement experiments were conducted on a full-scale test reinforced soil wall (Site-1) and an in-service highway reinforced soil wall (Site-2) in Kitami City, Hokkaido, Japan. ${ }^{(5)}$ Figure 8 shows the location of the test site, and Figs. 9 and 10 show a

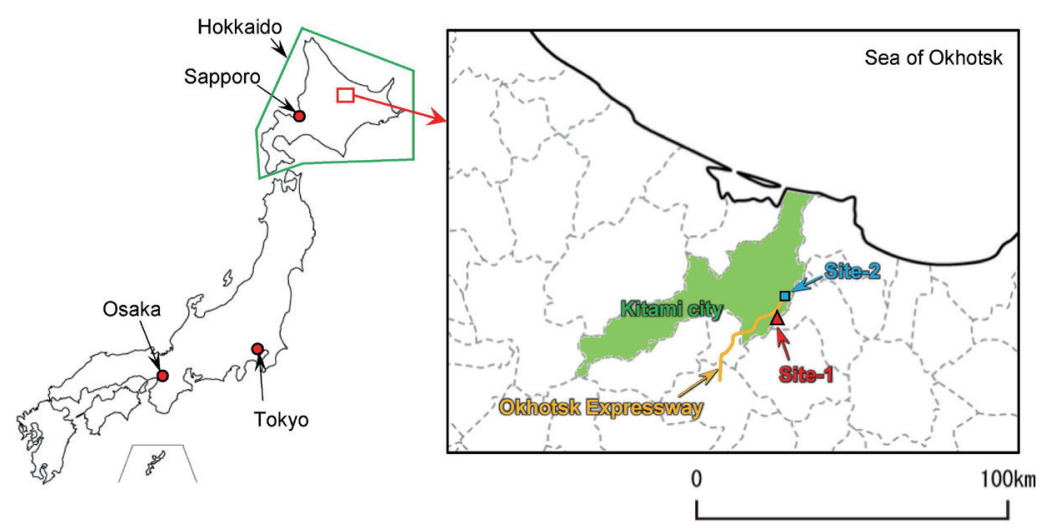

Fig. 8. (Color online) Location of test site.
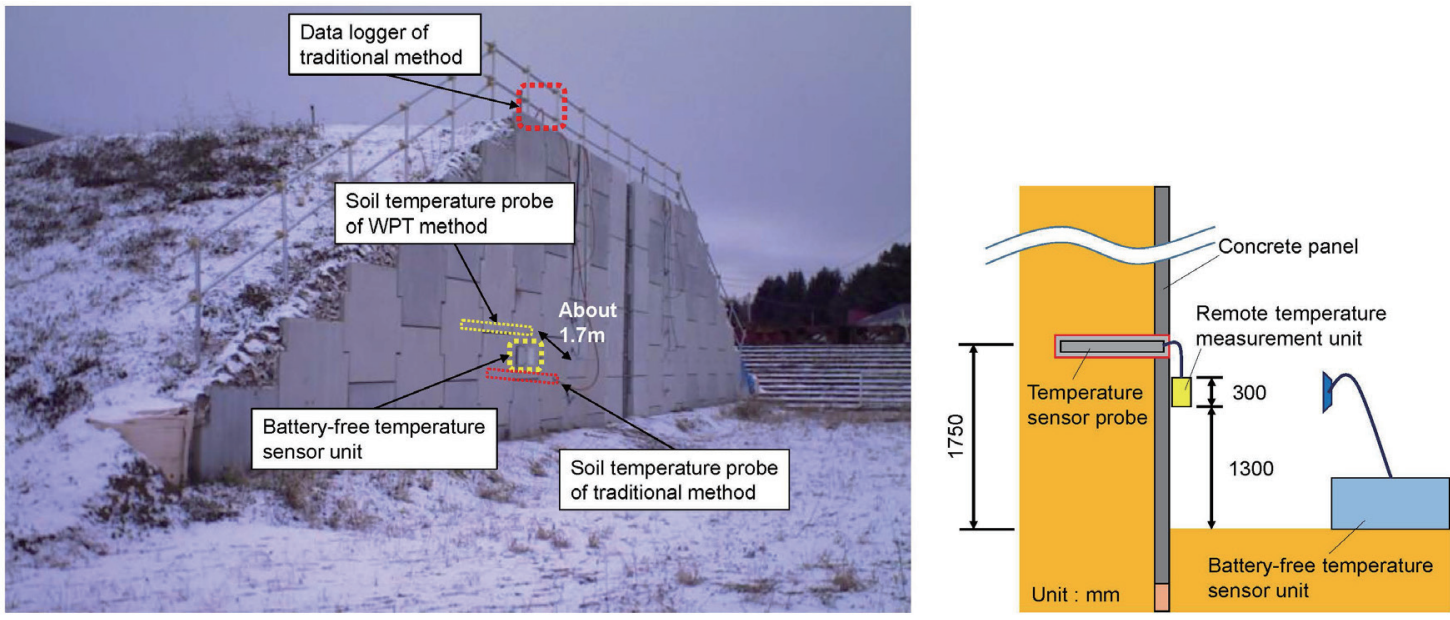

Fig. 9. (Color online) Overview (photograph) and schematic view of Site-1. 

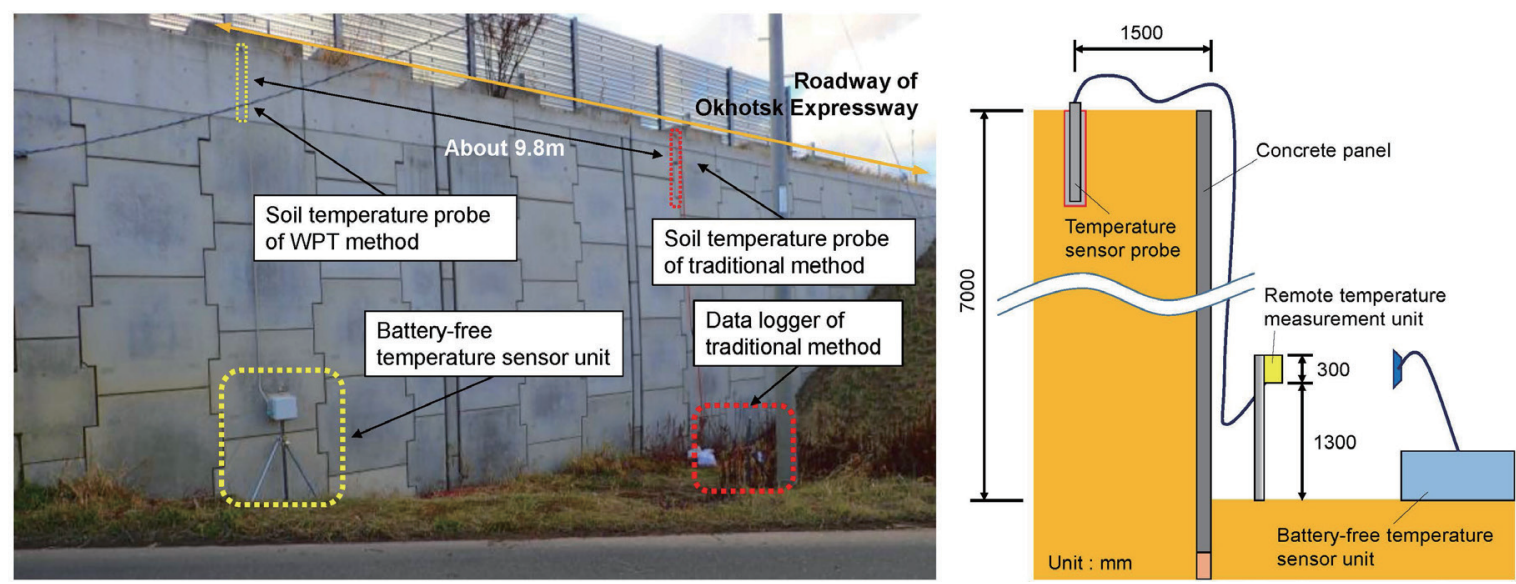

Fig. 10. (Color online) Overview (photograph) and schematic view of Site-2.

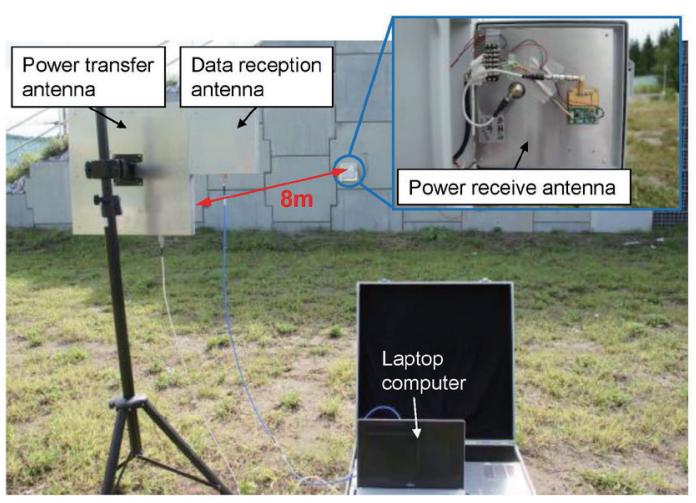

(a)

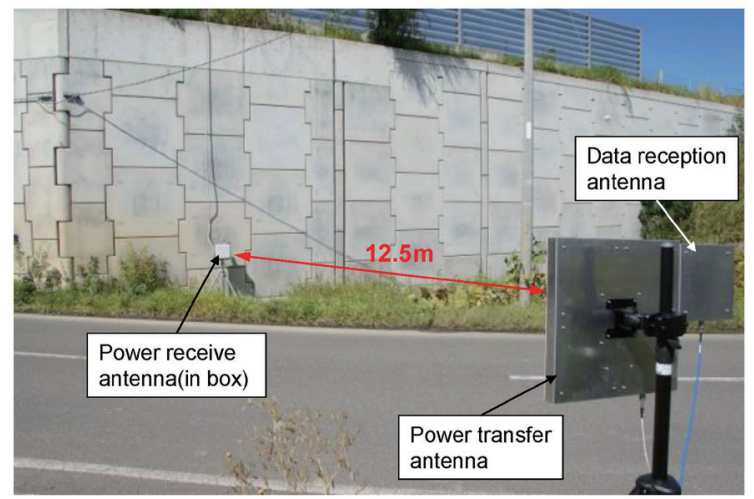

(b)

Fig. 11. (Color online) Setup of temperature measurement by WPT. (a) Site-1 and (b) Site-2.

general view of the reinforced soil wall and the layout of the measurement equipment. The 1.3-m-high WPT temperature sensor probe was placed horizontally on the 6-m-high reinforced soil wall of Site-1. The height of the reinforced soil wall of Site- 2 is about $7 \mathrm{~m}$, and the WPT temperature probe was installed at the top of the wall.

Figure 11 shows the WPT temperature measurement setup in Site-1 [Fig. 11(a)] and Site-2 [Fig. 11(b)]. The distance between the receiving antenna and the power receive antenna of the battery-free temperature sensor unit was $8 \mathrm{~m}$ in Site- 1 and $12.5 \mathrm{~m}$ across the road in Site-2.

The temperature measurement system of the traditional method consisted of a battery-powered data logger and a temperature sensor (measurement accuracy: $\pm 0.2^{\circ} \mathrm{C}$ ) wired together as shown in Fig. 12. The measurement frequency of the traditional method was once an hour, and the measurement period was from mid-November 2018 to mid-July 2019. 


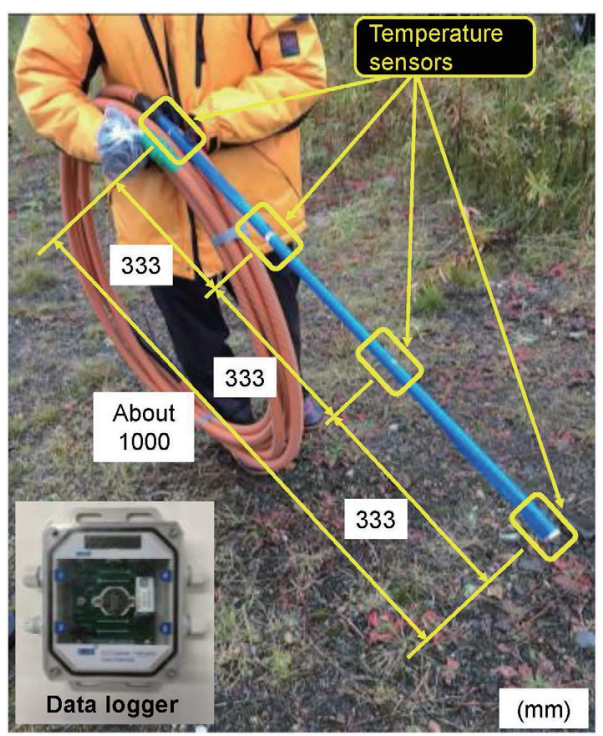

Table 5

Dates of temperature measurement by WPT.

Dec. 26, 2018

Jan. 10, 2019

Jan. 30, 2019

Mar. 26, 2019

Jul. 12, 2019

Fig. 12. (Color online) Soil temperature probe of traditional method.

\section{Results and Discussion}

In this study, the accuracy of the temperature sensor system using WPT was evaluated by placing the temperature measurement system using the traditional method in the vicinity of the temperature sensor system using WPT and comparing the measured values. Temperature measurement by WPT was carried out on the dates shown in Table 5. At the measurement distance of $8 \mathrm{~m}$ at Site-1, the measurement interval was about $4 \mathrm{~s}$. At the measurement distance of $12.5 \mathrm{~m}$ at Site-2, the measurement interval was about $3 \mathrm{~s}$. In outdoor operation, it is difficult to evaluate the temperature accurately because of the reflection of the transmission wave on the ground, but satisfactory data transmission results were obtained.

Figure 13 shows the seasonal variation of the soil temperature at Site-1 [Fig. 13(a)] and Site-2 [Fig. 13(b)]. In Site-1, the temperature dropped significantly in mid-February 2019, and the soil temperature at $x=333 \mathrm{~mm}$ was lower than $0{ }^{\circ} \mathrm{C}$. Therefore, the soil from the back of the concrete panel to the plane corresponding to $x=333 \mathrm{~mm}$ was frozen. In Site-2, the temperature sensor probe was perpendicular to the ground surface, and it was inferred that the temperature in the soil did not decrease. This was due to the adiabatic effect of snow accumulation in Site-2.(16) However, for the cases of $x=0 \mathrm{~mm}$ on December 26, 2018 at Site-1 and $y=0 \mathrm{~mm}$ on March 26, 2019 at Site-2, differences were observed between the values measured by the WPT and those measured by the traditional method. This may be due to the influence of local sunshine and snow cover.

Figure 14 shows a comparison of the temperature data measured by the WPT method and those measured by the traditional method. The difference between the temperature measured by WPT and the traditional method is about $\pm 1{ }^{\circ} \mathrm{C}$. Only one point showed a difference greater than $2{ }^{\circ} \mathrm{C}$, where the value measured by WPT was higher than the value obtained by the traditional method. This was due to the influence of local snow cover and solar radiation as shown in Fig. 12(b). 


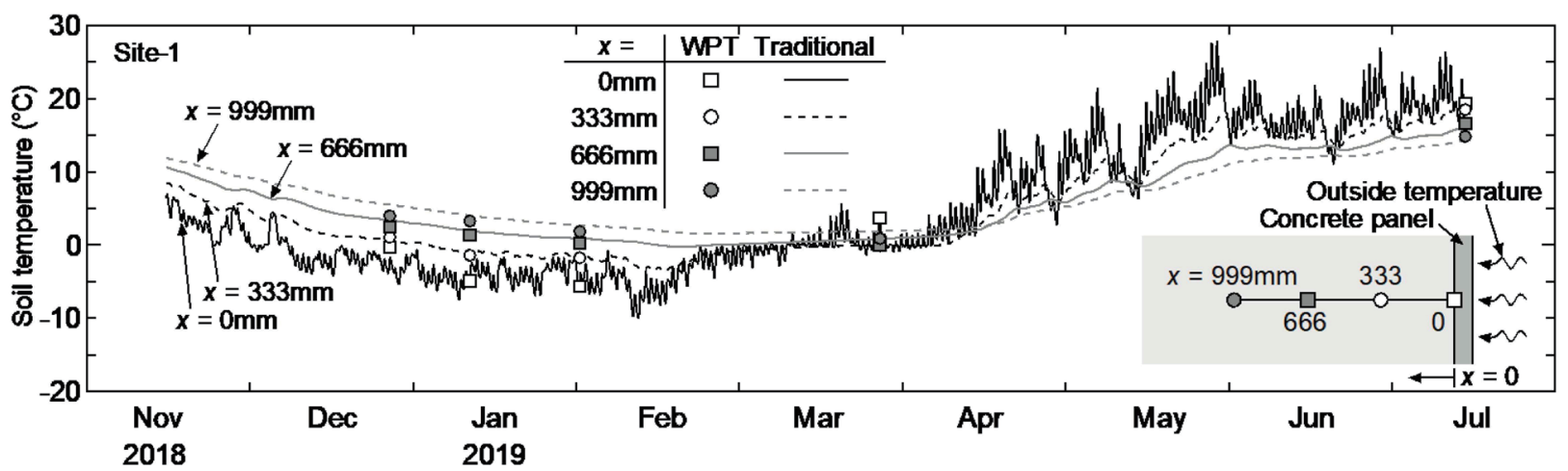

(a)

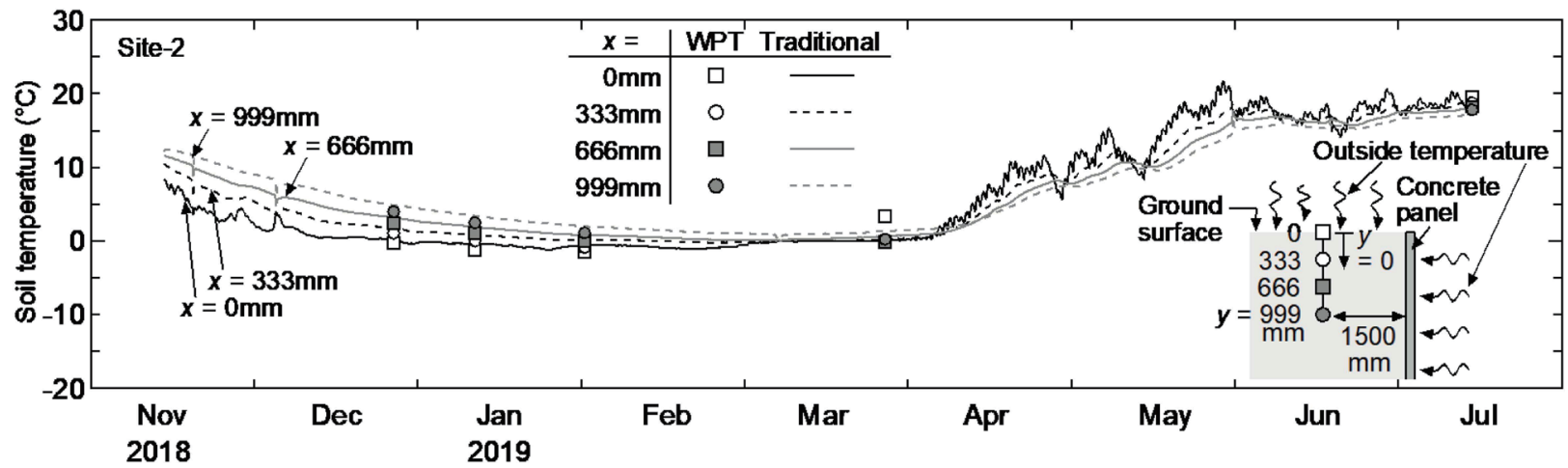

(b)

Fig. 13. Variations in soil temperature in (a) Site-1 and (b) Site-2 during monitoring (plots are WPT method, lines are traditional method).

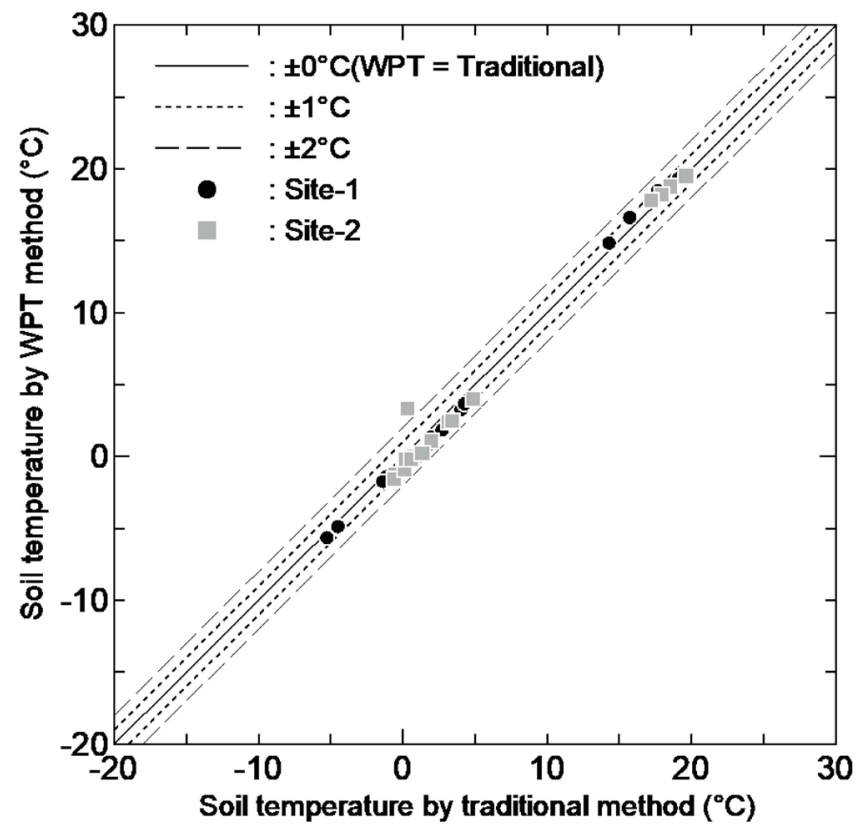

Fig. 14. Comparison between soil temperatures obtained by WPT method and traditional method. 
The above results show that the WPT method can measure soil temperature as accurately as the traditional measurement method. However, by increasing the interval between WPT measurements, the seasonal changes in the soil temperature can be obtained from 8 and $12.5 \mathrm{~m}$ away. In Japan, road structures are routinely inspected after major earthquakes and heavy rainfall. The results suggest that WPT can be used to obtain internal information of the ground with the same accuracy as before in such routine inspections. In addition, the measurement distances of 8 and $12.5 \mathrm{~m}$ are standard widths of roads in Japan, so the data can be obtained safely from the opposite side of the road from the target structure. For the observation on July 12, 2019, we constructed a vehicle-mounted WPT system, as shown in Fig. 15, to perform the measurement. In the future, we will attempt to develop a method to acquire multichannel soil temperature data by installing the system on a patrol car used for daily inspection as shown in Fig. 16. For this purpose, it is necessary to develop an antenna that can measure temperatures at multiple points.

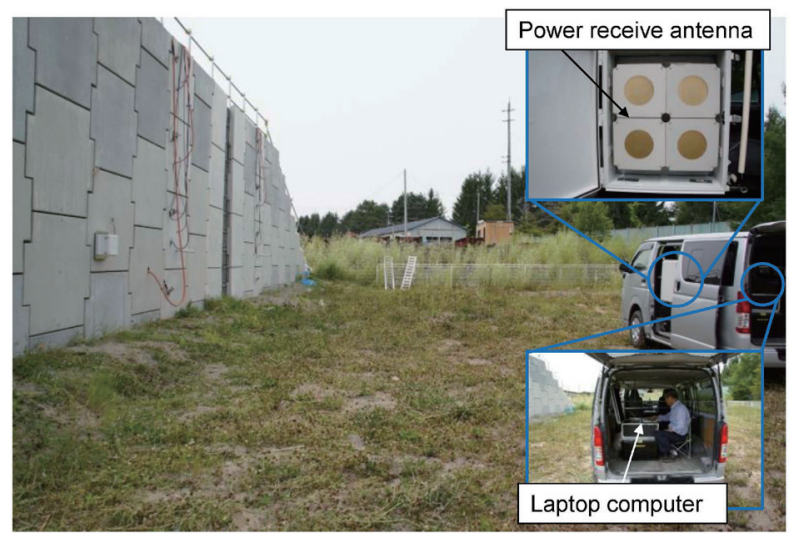

Fig. 15. (Color online) Schematic view of soil temperature measurement by in-vehicle WPT method on July 12, 2019.

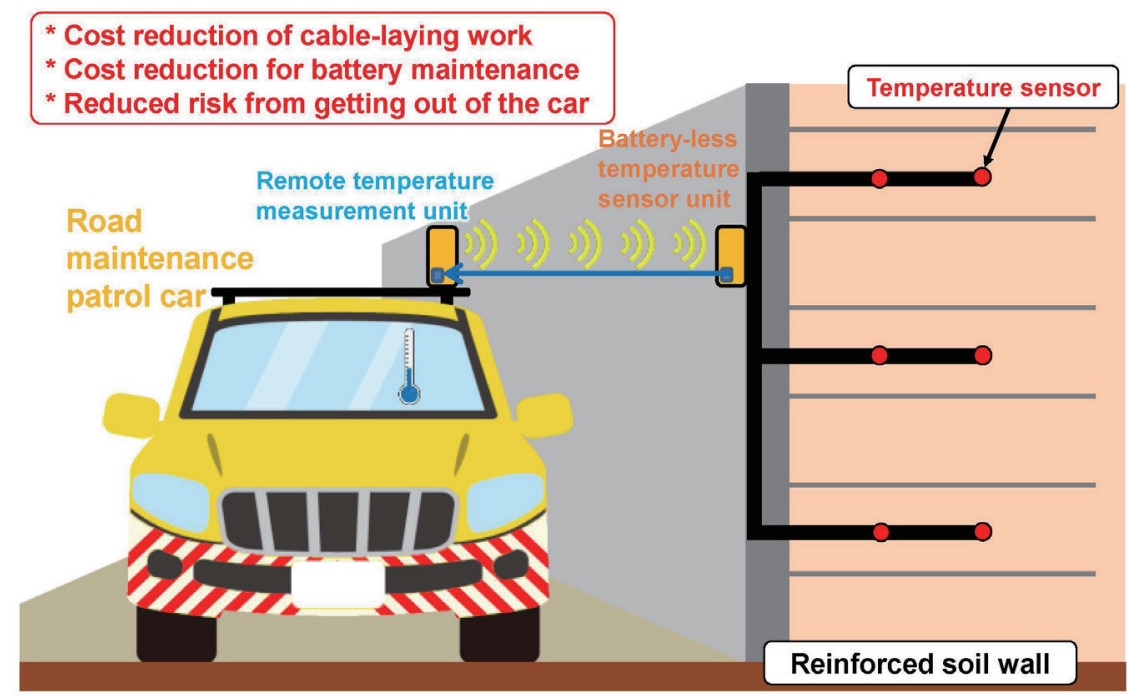

Fig. 16. (Color online) Final goal of this research on monitoring civil engineering structures by in-vehicle WPT method. 


\section{Conclusions}

In this paper, we presented a new method of measuring soil temperature based on WPT, which is a wireless method that does not require batteries. As a case study, we measured the soil temperature of two reinforced soil walls using the traditional method and the WPT method over nine months, and confirmed the consistency of the results. Although the study is still in progress, tentative but important insights were obtained as below.

(1) The maximum distance between the transmitting and receiving antennas was $12.5 \mathrm{~m}$ under the experimental conditions, and the soil temperature data can be obtained in about $3 \mathrm{~s}$ from this distance.

(2) The seasonal variation of the discrete temperature data obtained by the WPT method was consistent with that of the continuous temperature data obtained by the traditional method.

(3) The error of the temperature data obtained by the WPT and traditional methods was about $\pm 1^{\circ} \mathrm{C}$. Therefore, temperature changes in the soil can be determined by the WPT method.

\section{Acknowledgments}

The authors would like to express their gratitude to Japan Space Systems for the research grant. They were also helped by their colleagues, Prof. Naoki Shinohara of Kyoto University and Prof. Takayuki Kawaguchi of Kitami Institute of Technology, as well as by Mr. Yusuke Goto and Ms. Yuki Kikuchi, former students of Kitami Institute of Technology, in conducting the research. Their assistance is sincerely acknowledged.

\section{References}

1 F. Schlosser and H. Vidal: Bull de Liaison des Laboratoires Routiers Ponts at Chaussees 41 (1969) 101 (in French).

2 R. J. Bathurst, N. Vlachopoulos, D. L. Walters, P. G. Burgess, and T. M. Allen: Can. Geotech. J. 43 (2006) 1225. https://doi.org/10.1139/t06-076

3 J. Kuwano, Y. Miyata, and J. Koseki: Geosynth Int. 21 (2014) 1. https://doi.org/10.1680/gein.14.00008

4 S. Liu, T. Kawaguchi, S. Kawajiri, D. Nakamura, and A. Ogasawara: Geosynth. Eng. J. 35 (2016) 37. https://doi. org/10.5030/jcigsjournal.35.37

5 A. Ogasawara, Y. Goto, S. Kawajiri, H. Hashimoto, T. Kawaguchi, D. Nakamura, and S. Yamashita: Proc. 9th Int. Conf. GEOMATE (2019) USB.

6 G. A. Covic and J. T. Boys: Proc. IEEE. 101 (2013) 1276. https://doi.org/10.1109/JPROC.2013.2244536

7 S. Y. Hui: Proc. the IEEE. 101 (2013) 1290. https://doi.org/10.1109/JPROC.2013.2246531.

8 C. C. Mi, G. Buja, S. Y. Choi, and C. T. Rim: IEEE Trans. Ind. Electron. 63 (2016) 6533. https://doi.org/10.1109/ TIE.2016.2574993

9 Y.-S. Kim, J.-H. Kwon, Y. Lim, E.-J. Kim, D. Kim, and Y. S. Kim: Sens. Mater. 31 (2019) 3549. https://doi. org/10.18494/SAM.2019.2503

10 L. Pugi, A. Reatti, and F. Corti: JAT 2018 (2018) Article ID 8103140. https://doi.org/10.1155/2018/8103140

11 G. Liu, W. Jiang, W. Tan, and X. Lan: Sens. Mater. 32 (2020) 1141. https://doi.org/10.18494/SAM.2020.2525

12 K. M. Z. Shams and M. Ali: IEEE Sens J. 7 (2007) 1573. https://doi.org/10.1109/JSEN.2007.908230

13 F. Chen, N. Taylor, R. Balieu, and N. Kringos: Constr. Build Mater. 147 (2017) 9. https://doi.org/10.1016/j. conbuildmat.2017.04.149

14 N. Shinohara: IEEE J. Microwaves 1 (2021) 218. https://doi.org/10.1109/JMW.2020.3030896

15 J. Niu and G. Y. Li: J. Commun. Inf. Networks 4 (2019) 1. https://doi.org/10.23919/JCIN.2019.8917868

16 T. Hirota, Y. Iwata, M. Hayashi, S. Suzuki, T. Hamasaki, R. Sameshima, and I. Takayabu: JMSJ 84 (2006) 821. https://doi.org/10.2151/jmsj.84.821 
